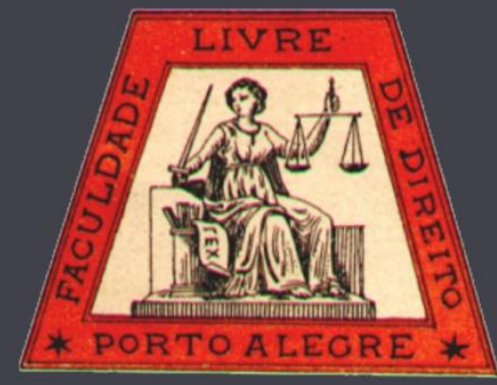

\title{
Sem critérios: a abertura oportunizada ao magistrado para a aceitação de prova ilicitamente derivada
}

No criteria: the opening provided for the judge to accept illegally derived evidence

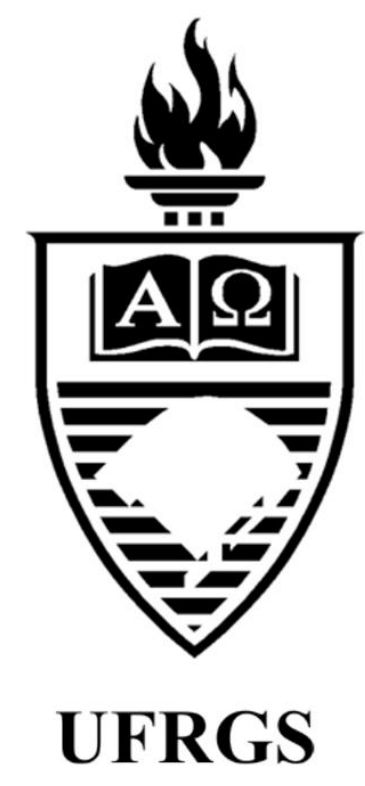

Antônio Paulo Soares Lopes da Silveira Pontifícia Universidade Católica do Rio Grande do Sul

\section{Mariana Azambuja}

Pontifícia Universidade Católica do Rio Grande do Sul 


\title{
Sem critérios: a abertura oportunizada ao magistrado para a aceitação de prova ilicitamente derivada
}

\author{
No criteria: the opening provided for the judge to accept illegally derived evidence
}

\author{
Antônio Paulo Soares Lopes da Silveira*
}

Mariana Azambuja**

\section{REFERÊNCIA}

SILVEIRA, Antônio Paulo Soares Lopes da; AZAMBUJA, Mariana. Sem critérios: a abertura oportunizada ao magistrado para a aceitação de prova ilicitamente derivada. Revista da Faculdade de Direito da UFRGS, Porto Alegre, n. 35, p. 268-286, dez. 2016.

\section{RESUMO}

O trabalho tem como proposta uma reflexão sobre artigo 157 do Código de Processo Penal, a partir das reformas introduzidas pela Lei $\mathrm{n}^{\circ}$. 11.690/2008, na parte em que regulou a matéria relativa a prova ilícita por derivação. $\mathrm{O}$ objetivo central da pesquisa foi realizar uma análise crítica à abertura que o novo texto do dispositivo legal oportunizou ao magistrado para interpretar a aceitação da prova ilicitamente derivada. Outra questão bastante analisada foi o esvaziamento do texto constitucional que veda a utilização da prova ilícita no processo, haja vista que ocorreu uma verdadeira relativização da previsão. A análise da teoria dos frutos da árvore envenenada, bem como dos institutos de relativização das provas ilícitas criados no ordenamento jurídico norte-americano foram abordados, pois é a partir de sua introdução no ordenamento jurídico brasileiro, pela aludida reforma, que se consolidou a abertura para aceitação das provas ilícitas.

\section{PALAVRAS-CHAVE}

Processo Penal. Provas ilícitas por derivação. Artigo 157. Frutos da árvore envenenada.

\begin{abstract}
The paper aims to reflect on the Article 157 of the Criminal Procedure Code, from the reforms introduced by Act No. 11,690 of 2008, to the extent that it regulated the matter concerning illegal evidence by derivation. The main objective of the research was to make a critical analysis of the opening that the new text of the legal provision provided for the judge to interpret the acceptance of illicitly derived evidence. Another issue fairly analyzed was the emptying of the constitution text, which prohibits the use of illegal evidence in the case, given that there was a real relativization of the provision. The analysis of the theory of the fruits of the poisonous tree, as well as the relativization institutes of illegal evidence created in the American legal system were addressed, because it is since its introduction into the Brazilian legal system, by the aforesaid reform, that the opening for acceptance of illegal evidence was consolidated.
\end{abstract}

KEYWORDS

Criminal Procedure. Illegal evidence by derivation. Article 157. Fruits of the poisoned tree.

\section{SUMÁRIO}

Introdução. 1. Provas ilícitas por derivação: fruit of the poisonous tree doctrine. 2. A utilização da teoria no Brasil: a reforma do Código de Processo Penal introduzida pela Lei $N^{\circ} 11.690 / 2008$. 3. A ausência de critérios objetivos para a utilização da prova ilícita por derivação. 4. O retrocesso do texto legal em desacordo com as garantias constitucionais em um Estado Democrático de Direito: as consequências da ausência de critérios. Conclusão. Referências.

\footnotetext{
* Mestre em Ciências Criminais pela Pontifícia Universidade Católica do Rio Grande do Sul - PUCRS, 2016. Especialista em Ciências Criminais pela Pontifícia Universidade Católica do Rio Grande do Sul - PUCRS, 2013 e Bacharel em Direito pelo Centro Universitário Ritter dos Reis, 2012. Advogado.

** Mestre em Ciências Criminais pela Pontifícia Universidade Católica do Rio Grande do Sul - PUCRS, 2016. Especialista em Ciências Penais em 2014 e graduada em 2012 pela Pontifícia Universidade Católica do Rio Grande do Sul - PUCRS.
} 


\section{INTRODUÇÃO}

Inegável que a prova no processo penal propicia ao julgador reconstruir os fatos préexistentes ao processo, inatingíveis em sua plenitude em virtude de sua singularidade e irrepetibilidade, e posteriormente sentenciar de acordo com as provas apresentadas.

Francesco Carnelutti (CARNELUTTI, 2006, p. 275-276) compara as provas com as chaves, mediante as quais o juiz utiliza para abrir as portas do desconhecido, tendo por objetivo saber o que não sabe. Por tratar-se de uma ação dos homens, não existe como atingir o resultado de forma perfeita, porém exista possibilidade de atingir um resultado próxima a sua finalidade. "Às vezes a porta se abre inteiramente; às vezes, somente um pouco; não raro permanece fechada $[\ldots] "$.

Nicola Framarino Malatesta (MALATESTA, 2001, p. 69) ao trabalhar o conceito de prova, ensina que "[...] a certeza é a única base para a condenação judicial. Considerando-se assim, a prova é a relação concreta entre a verdade objetiva e a certeza subjetiva. [...] prova é a relação concreta entre a verdade e a convicção racional."

Entretanto, discordamos das concepções clássicas nos firmando ao pensamento de Nereu Giacomolli (GIACOMOLLI, 2014, p. 160-161), o qual entende que esta concepção de que a prova permite o apoderamento da verdade não deve vigorar mais no processo penal brasileiro, $o$ magistrado não deve buscar a verdade, mas decidir quando for provocado, evitando-se assim um ativismo judicial que afasta qualquer imparcialidade possível.

Portanto, a prova é um meio, um instrumento para conhecer $\mathrm{o}$ fato, um acontecimento histórico que se pode conhecer, um caminho para que o juiz possa criar sua convicção sobre o caso concreto (ÁVILA, 2006, p. 46).
A reconstrução dos fatos é abrangida por diversos meios e mecanismos de formulação de provas, sendo estes limitados pela Constituição Federal, que alicerça a negativa da admissão das obtidas ilicitamente.

Nesta trama é importante não olvidar que o processo é uma garantia constitucional desenvolvida através do avanço dos direitos humanos, culminando na criação de mecanismos de proteção processual; neste vértice, a prova, como se observa é uma das maiores garantias de defesa do acusado, pois o Estado Acusationes, utilizando-se do processo, deverá através das provas, realizar a reconstrução dos fatos para averiguar a existência do crime (GIACOMOLLI, 2008, p. 21).

Nesse passo, a necessidade de humanização do Direito Penal e Processo Penal contra a insegurança e o deleite do Estado em sua sede de penalização, bem como de utilização da tortura e castigo como forma de investigação, passou a ser atendida pelo surgimento das garantias processuais, ou como é trabalhado no direito norte-americano Due process of law (SAMPAIO, 2007, p. 54).

A perspectiva garantista surge como uma forma de limitar o poder e evitar a opressão, tanto pública quanto privada. Assentado no princípio da legalidade estrita, essa visão de processo penal eleva as garantias processuais a pressupostos da jurisdição penal (PRADO, 2012, p. 69).

Assim, no Estado de Direito, as decisões devem ser produto de um processo penal admissível e válido, a partir do respeito aos direitos fundamentais dos cidadãos, tendo o juiz a função de zelar pela concretização destes direitos constitucionalmente previstos (PRADO, 2012, p. 69-70).

Conseguinte, são elementos de provas todos os meios lícitos utilizados para o convencimento do juiz em relação aos fatos em apreciação, para que seja possível o alcance da 
verdade jurídica dos crimes imputados a certa pessoa.

Aqui se funda o princípio da presunção de inocência, consagrado pelo artigo $5^{\circ}$, inciso LVII da Constituição Federal, considerado o reitor do processo penal, podendo-se verificar a qualidade de um sistema penal pela eficácia na observância de tal princípio.

Deste modo, a jurisdicionalidade é necessária para a formação da prova, verificando-se que o cometimento de um delito, só será reconhecido mediante um processo regular, não podendo ninguém ser considerado culpado e submetido a uma pena, sem que haja o devido processo legal, com sentença transitada em julgado. (LOPES JR. 2014, p. 160).

Entrando no mérito da presente pesquisa, após necessária explanação, o artigo $5^{\circ}$, inciso LVI, da Constituição Federal Brasileira, proibiu o uso de provas ilícitas. O objetivo central é salvaguardar os direitos individuais do cidadão como: direito à intimidade; à privacidade; à imagem e à inviolabilidade do domicílio.

O Código de Processo Penal, regulamentando os mandamentos contitucionais, prevê que todas as provas ilícitas deverão ser desentranhadas do processo, sob pena de nulidade das decisões que forem nelas fundamentadas.

Em decorrência da prova ilícita, se observa uma desinência da mesma, a prova ilícita por derivação, que teve sua vedação consagrada e importada dos julgados Norte Americanos, conhecida como a teoria fruits of the poisonous tree, sendo utilizada primeiramente pelas jurisprudências dos tribunais pátrios.

Com o advento da Lei $\mathrm{n}^{\circ} 11.690$, de 09 de junho de 2008, foi finalmente introduzida a teoria no Código de Processo Penal, restando positivada no artigo 157, parágrafo primeiro e segundo.

Com a reforma introduzida pelo citado édito legal, verificou-se a meta de articular as várias dimensões da questão, sob a ótica do sistema acusatório de processo, elevando-se os preceitos constitucionais de garantias, primandose por uma qualidade da decisão judicial (pela melhor prova possível), relegando ao acusador e investigador a necessidade de empregar meios de prova qualificados, exigindo-se um maior cuidado com as provas ilícitas (PRADO, 2014, p. 38-41).

Entretanto, ambos os parágrafos do dispositivo ampliam a margem de interpretações sobre o que é derivação ilícita, constituindo uma verdadeira abertura para qualquer utilização e conceituação pelos tribunais pátrios.

Verificou-se um grave problema quanto às hipóteses probatórias, pois, embora exista a vedação de sua utilização, a Lei propiciou aos magistrados uma ampla aceitação das hipóteses de cabimento da prova por derivação.

Observou-se que a critério do julgador, qualquer prova derivada pode ser aceita, uma vez que o dispositivo legal permite uma análise deveras subjetiva de sua aceitação, o que fere aos princípios constitucionais de ampla defesa e contraditório.

Em interpretação literal ao dispositivo constitucional e processual penal, obtemos como resultado, efeito fundante sobre o reconhecimento da prova ilícita, a impossibilidade absoluta da utilização desta prova, observando-se também a regra norteamericana da rules of exclusion, a inadmissibilidade da prova ilícita (ilegacy obtained evidence), regras que observaram a IV emenda do país (AVOLIO, 2003, p. 61).

Impõem-se observar qual a possibilidade de aceitação da prova ilícita por derivação, avaliar se as exceções contidas no dispositivo legal para sua admissibilidade fragilizam e esvaziam a garantia constitucional da vedação da prova ilícita, permitindo que sejam utilizadas tais provas no processo penal. 
1 PROVAS ILÍCITAS POR DERIVAÇÃO: FRUIT OF THE POISONOUS TREE DOCTRINE
A
discussão
introduzida
com
o reconhecimento da prova ilícita gira em torno da extensão de seus efeitos, pois uma prova vedada pode constituir derivações probatórias. Ao reconhecer a prova ilícita devemos observar se somente esta prova deverá ser conspurcada dos autos, tendo em vista que a prova derivada foi constituída através da ilícita.

Sobre o tema, autores como Ada Pellegrini Grinover (GRINOVER, 2011, p. 130) e Guilherme de Souza Nucci (NUCCI, 2009, p. 358), concordam que a ilicitude das provas se transmite às derivadas, devendo ser igualmente banidas do processo. Entretanto, concordam com os meios de relativização dessa vedação, desmoronando o castelo de cartas através da subjetividade.

Adentrando mais ao assunto, o reconhecimento das provas ilícitas derivadas se relaciona com a Teoria dos Frutos da Árvore Envenenada, que se caracteriza na constatação lógica de que os frutos advindos da árvore envenenada, também serão envenenados, tal figura de linguagem tenta explicar através de uma metáfora, a questão da prova lícita, que advém de uma prova ilícita (GIACOMOLLI, 2014, p. 167).

A teoria foi trabalhada na Suprema Corte dos Estados Unidos da América, no caso Mapp v. Ohio, 367US643 (1961). O Magistrado do caso entendeu da impossibilidade de uma prova vedada produzir efeitos nos autos, o que culmina a proeminente lógica de que uma prova derivativa seria um efeito, e, portanto, não poderia ser utilizada, respeitando o que as emendas IV, V e VI da Constituição Americana (RAMOS, 2006, p. 124).

Quando o procedimento inicial viola garantias constitucionais, a ilegalidade se estenderá para os demais atos que dela se ocasionem. Desse modo, o resultado do procedimento precípuo não pode ser utilizado como elemento probatório, bem como as outras provas que são fruto da ilegalidade originária (QUEIJO, 2003, P. 384).

Nesse ponto a jurisprudência norteamericana há muito trabalha a ideia de provas ilícitas por derivação. No caso Silverthone Lumber Co. v. United States, consolidou-se a fruit of the poisonous tree doctrine (teoria dos frutos da árvore envenenada), onde o juiz adjunto do caso, Oliver Wendell Holmes Jr., formulou a ilustríssima observação "a essência da norma que proíbe a aquisição de uma prova de uma certa maneira não se limita a dizer que ela não pode ser utilizada em juízo, mas reza que ela não pode ter efeito algum." (RAMOS, p. 123).

No sistema norte-americano, a proibição das provas obtidas ilicitamente tem por objetivo atender uma função de limitação à atuação policial, cuja atribuição no processo do país é também trazer aos autos as provas (fact finding) necessárias ao caso (case). Esta fase é conhecida como discovery relaciona-se com as provas colhidas pela acusação e defesa, cuja idoneidade garante sua apreciação pelo Tribunal do Júri (trial by jury). Tais proibições teriam a ambição de atender as regras do jogo, as quais são garantidas pelo juiz, não apenas aos direitos de personalidade, tendo por primado o respeito à cláusula due process of law. Esse sentido de proibição é duplo sentido: “dirige-se em primeiro lugar, aos agentes policiais a fim de se coibir atividades atentatórias aos direitos fundamentais; em segundo, os direitos fundamentais servem de parâmetro à polícia, não podendo infringi-los, sob pena de exclusão da prova" (JACOBSEN, 2010, p. 388).

Nesse passo, importante relevar que no processo norte-americano, a questão verdadeiramente decisiva em debate na fase do 
processo relativa à admissibilidade dos meios de prova é determinar se terá ocorrido uma violação da lei por parte da polícia (COSTA ANDRADE, 1992, p. 144-145).

Aqui tem-se que tomar ciência que, a partir de movimentos de law and order (lei e ordem) e a the broken windows theory (teoria das janelas quebradas), há muito estudados pelas escolas criminológicas, relacionados à segurança pública e expansão do modelo repressivo, também ocorreram a criação de diversas exceções à regra das exclusionary rules (JACOBSEN, 2010, p. 389). Logo, exceções relacionadas à atuação policial e investigatória, que desrespeitam direitos fundamentais constitucionalmente previstos, em virtude de uma possível "segurança".

Nesta trama, importante ressaltar que o próprio ordenamento jurídico americano prevê exceções quanto à regra dos Frutos da Árvore Envenenada, utilizando-se das proposições mais recorrentes, good faith exception, inevitable discovery, independente source, e a urgent taint (FILHO, 1997, p. 108).

O good faith exeption (exceção de boa-fé), nada mais é do que a relativização do princípio do exclusionary rule (regra da exclusão), onde existe a confiança dos policiais em uma determinação judicial, observando-se a razoabilidade em virtude do potencial conhecimento da irregularidade da prova. Portanto, nada mais é do que a atuação de boa-fé dos policiais na formação da prova em virtude do cumprimento de ordem judicial, que afasta a ilicitude da prova pelo caráter preventivo atribuído a seu reconhecimento, como realça a jurisprudência norte-americana (FEITOZA, 2006, p. 196).

A inevitable discovery (descoberta inevitável), nada mais é do que afastar a incidência da vedação da prova ilícita, pois seria inevitável que esta prova fosse encontrada tardiamente pela autoridade policial em atividades investigatórias lícitas (QUEIJO, 2003, p. 386).

A urgenttaint (contaminação expurgada) é utilizada quando um vício anterior for expurgado pelo ato independente praticado pelo acusado ou por uma terceira parte, que interrompa a corrente causal entre a ilicitude e a prova, de uma forma que a prova não mais seja considerada decorrente da ilicitude (FEITOZA, 2006, p. 201).

Ao nos utilizarmos de uma prova ilícita, e, dela advirem outras provas, mesmo que por meios lícitos, a partir das exceções da regra de exclusão, constituiríamos uma temerosa situação.

Como acentua Ricardo Gloeckner Jacobsen (JACOBSEN, 2010, p. 386-387), nos casos de extrema dificuldade probatória (principalmente os relacionados com as organizações criminosas ou quadrilhas) acabam sendo admitidas provas oriundas de uma ilicitude originária a fim de ser evitada uma possível impunidade - cominada no velho discurso.

$\mathrm{O}$ autor continua descrevendo que a justificativa é semelhante àquela utilizada para um dever de criminalização e expansão criminal. Pois, em certos casos, o Estado deve proteger o direito da sociedade e o interesse coletivo. Uma verdadeira interpretação relacionada ao princípio da vedação da proteção deficiente.

No entanto, entende-se que o agente que deu causa ao fato, teria a liberalidade da produção de provas ilícitas, visando o alcance lícito de outras provas. Tal modalidade seria totalmente incoerente numa análise axiológica da ação em comento, pois a valoração do fato gerador deve ser atribuída para a sua derivação, isto é, se foi ilícito, e se resultou em uma derivação licita, deve esta ser valorada como ilícita, pela origem que teve, objetivando o devido respeito aos princípios constitucionais, não devendo ser ponderadas exceções que esvaziam o objetivo fundante (PACELLI, 2011, p. 349). 
2 A UTILIZAÇÃO DA TEORIA NO BRASIL E A REFORMA DO CÓDIGO DE PROCESSO PENAL INTRODUZIDA PELA LEI N ${ }^{\circ} 11.690 / 2008$

No Brasil, como já abordado, a vedação da prova ilícita por derivação foi constituída a partir da Teoria dos Frutos da Árvore Envenenada (the fruits of the poisonous tree), importada da jurisprudência dos tribunais norte-americanos, pelos tribunais brasileiros (GIACOMOLLI, 2008, p. 39).

O ordenamento jurídico brasileiro se apropriou da teoria norte-americana, utilizando-a no Código de Processo Penal, com a reforma pela Lei n 11.960/2008, pois anteriormente não existia previsibilidade legal sobre a prova ilícita por derivação, mas tão somente entendimento jurisprudencial sendo aplicado pelo Supremo Tribunal Federal, como será observado no próximo tópico.

O artigo 157, $\S 1^{\circ}$, do Código de Processo Penal, introduzido pela referida Lei, veda a utilização das provas ilícitas por derivação. Porém nos demais parágrafos há a exceção da regra de utilização da prova ilícita, do mesmo modo que no direito americano, prevendo o parágrafo $2^{\circ}$, in verbis: "Considera-se fonte independente aquela que por si só, seguindo os trâmites típicos e de praxe, próprios da investigação ou instrução criminal, seria capaz de conduzir ao fato objeto da prova".

Observa-se no dispositivo legal que o legislador brasileiro introduziu apenas dois princípios de relativização da derivação de provas ilícitas: quando não evidenciado o nexo de causalidade entre as duas situações e quando as provas derivadas puderem ser obtidas por uma fonte independente das primeiras (GIACOMOLLI, 2008, p. 40).

A falta de nexo de causalidade é a relação de causa e efeito, significando a necessidade de que seja observada a conexão entre a prova ilícita e a derivada, ou que essa conexão não seja tênue. Relacionada a essa problemática a teoria da fonte independente, o que significa que as provas poderiam ser encontradas de outra maneira (LOPES JR. 2014, p. 615).

Para Nereu José Giacomolli

(GIACOMOLLI, 2008, p. 43) o nexo de causalidade representa:

[...] a conexão, a dependência ou o liame entre as duas situações: ilicitude e licitude (fontes, meios ou metodologia de busca da prova). Trata-se de verificar se há elos com a anterior ilicitude, com a identidade vinculante ou, como refere Knijnik, trata-se de saber se a prova obtida foi adquirida com abstração ou não da árvore venenosa.

A prova não se relaciona com os fatos que a geraram, não sendo contaminada por eles. Para ilustrar, utilizando-se do exemplo de Eugênio Oliveira Pacelli, um policial ao avistar um veículo de última geração, no trânsito, desconfiou tratar-se de furto, pois quem dirigia era pessoa de cor negra. A apreensão do veículo em virtude do panorama que se apresenta, pois originária de atitude discriminatória por parte do agente do Estado, poderia tornar a prova ilícita. Porém, nada impediria que eventuais testemunhas que presenciaram o furto fossem ouvidas e a autoria do delito fosse comprovada. Nesse ponto, nota-se claramente que a apreensão não teria nexo de causalidade com o reconhecimento feito por testemunho, sendo essa prova válida (PACELLI, 2011, p. 350).

Portanto, quando a prova analisada não possuir nexo de causalidade com a ilicitude praticada, quando possuir uma fonte independente da ilicitude, sem contaminar-se, será admissível.

Outra relativização quanto à prova ilícita por derivação, pode ser observada no tocante a teoria da descoberta inevitável, se caracterizando por utilizar-se da premissa de que a prova poderia posteriormente ser encontrada de outra forma. 
Exemplo disso, o primeiro precedente sobre o tema nos tribunais norte-americanos. $\mathrm{O}$ crime cingia-se no fato de que o acusado havia matado uma criança e escondido seu corpo. Assim, foi objetivada a busca da criança com 200 voluntários divididos em zonas de atuação, no entanto, durante as buscas, a polícia ilegalmente obteve a confissão do autor do delito, que indicou o local onde se situava o corpo da criança. Porém a prova foi considerada lícita, visto que, pela estrutura montada de buscas, seria inevitável que o corpo da criança fosse encontrado (LOPES JR. 2014, p. 615).

Aqui se observa claramente a necessidade de analisar a prova ilícita, e considerar se realmente existiram outros meios jurídicos concretos, que ocasionariam a formação do elemento de prova.

Mantém-se a ilicitude anterior conjuntamente com a prova, diferente do que ocorre com a fonte independente, que se afasta desta ilicitude, pois não possui nexo de causalidade (GIACOMOLLI, 2008, p. 47).

Portanto, admite-se a prova, ainda que exista eventual relação de causalidade ou dependência entre as provas (a ilícita e a descoberta), evitando-se a contaminação de todas as provas que sejam subsequentes a inicialmente ilícita (PACELLI, 2011, p. 350).

Importante ressaltar que o ônus de provar a descoberta inevitável está, inteiramente, com a acusação (LOPES JR. 2014, p. 615).

A reforma legislativa quanto à vedação das provas ilícitas que positivaram também a impossibilidade de utilização de provas ilícitas por derivação, é amplamente criticada pela doutrina, em razão da amplitude do conceito sobre as exceções dispostas no novo dispositivo legal, que incorporou elementos norteamericanos, relativizando as provas derivadas de forma a deslegitimar sua vedação.

Nesse norte é que se funda o cerne crítico, pois aqui nesse ponto o legislador equivocou-se na reforma introduzida.

A Lei ${ }^{\circ} 11.960 / 2008$ foi promulgada com o objetivo de regulamentar normativamente a formação, obtenção e valoração da prova no Processo Penal. Observa-se que a nova lei somente reformulou os artigos do Código de Processo penal, $155 ; 156 ; 157 ; 159 ; 201 ; 210$; 212; 217 e 386, modificando os dispositivos legais existentes, ocorrendo à revogação tácita de alguns deles (FARIAS, 2010, p. 385).

Aqui se observa o caráter garantista trazido pela reformulação dos referidos artigos, pois se nota pela nova redação que se tentou extirpar do Código de Processo Penal o animus inquisitorial do momento histórico em que foi formulado.

O nosso código processual foi originado na época dos regimes totalitários europeus e no momento que o Brasil também vivia um regime totalitário, conhecido como a Era Vargas, em 1941, sendo os mecanismos importados, principalmente, do regime fascista italiano, o que é uma dissonante do ordenamento jurídico existente em pleno século XXI, onde o que se preleciona são as garantias constitucionais do acusado, pelo Estado. (TASSE, 2009, p. 20-21).

Como aborda Nereu José Giacomolli (GIACOMOLLI, 2008, p. 01-02), o Código Penal e de Processo Penal, não romperam com a base epistemológica e política da década de quarenta, ainda existe a supremacia do ius puniendi sobre o direito a liberdade, se inflamando a busca da verdade material a todo custo, até via ex officio. Observando que, até depois da reforma, ainda existe a possibilidade do magistrado de ofício produzir provas.

Neste ponto, ao analisar a matéria, Aury Lopes Junior (LOPES JR., 2009, p. 09) refere tratar-se de uma reforma pontual no arcaico Código de Processo Penal, que pode ser comparado a uma colcha de retalhos, pelas inúmeras Leis que tentaram modificá-lo para que se adaptasse ao que preleciona a Constituição Federal. 
Afirma que a problemática se situa na falta de um princípio unificador que impede o alcance de uma consistência e coerência sistêmica, qualificando a reforma como essencialmente minimalista, ilógica e geradora de diversas dicotomias e lacunas internas. Ainda, sustenta que, a reforma pontual, não quebra com o elemento histórico inquisitorial do Código de Processo Penal, pois uma nova prática convivendo com uma velha prática propicia um terreno fértil para a manutenção do status quo ante, isto é, não há como utilizarmos dois regimes ao mesmo tempo, como validar garantias constitucionais, utilizando-se, também, de práticas inquisitivas (LOPES JR., 2009, p. 09).

Com interpretação semelhante sobre as reformas parciais introduzidas pela Lei, Flaviane de Magalhães sustenta a ideia de que o direito processual penal deve ser analisado como um sistema, um conjunto, necessitando de uma interligação de suas disposições, existindo, portanto, um princípio unificador, determinandose uma ideia única (BARROS, 2009, p. 39).

Observando o que prescrevem os autores, a nova Lei encontra-se deslocada na base Processual Penal existente, pois visa à proteção das garantias advindas com a promulgação da Constituição Federal de 1988, portanto, como consabido, eleva o direito penal acusatório, consistindo em uma ilha de garantismo no mar inquisitorial dos textos legais penais brasileiros, anteriores à Constituição.

Neste passo, Augusto Jobim do Amaral (AMARAL, 2014, p. 334-335) alicerça que a justiça criminal brasileira institucionalizou $\mathrm{o}$ pensamento inquisitorial, perpassando por diversos momentos históricos, subsistindo até aos marcos constitucionais democráticos.

Existe uma cristalização de uma lógica autoritária naqueles que presentificam cotidianamente o sistema penal, estabelecendo um controle social punitivo institucionalizado, mesmo com reformas ancoradas em um ambiente constitucional democrático (AMARAL, 2014, p. 334).

Assim, a Lei foi erigida sobre fundações inquisitoriais, e como foi abordado, não há formas de se estabelecer um sistema misto, conseguinte, não existe forma de utilizar-se de um sistema que restringe garantias processuais com outro que visa garanti-las, neste ponto imperioso frisar-se que a prova ilícita, de acordo com essas garantias, deve sempre ser expurgada dos autos, como também seus efeitos, e suas derivações.

Posição bastante esclarecedora sobre o tema das reformas introduzidas pela Lei em comento é a de Fernando Gerson, postulando que toda alteração legislativa de grande mudança representa um desafio para os operadores do direito, como também para a academia (GERSON, 2009, p. 69).

Assim, introduziu a ideia de que qualquer reforma efetuada significa o fim de uma égide normativa que se encontra assentada em práticas jurídicas, tendo por objetivo aperfeiçoar o direito. Neste passo, define que as reformas, principalmente no que concerne direito processual penal, encontram grandes problemas na regulação das duas grandes zonas de tensão existentes, quais sejam, o status libertatis do Indivíduo conflitante com o jus puniendi Estatal (GERSON, 2009, p. 69).

$\mathrm{O}$ dispositivo legal em estudo criou esta dicotomia, entre o sistema acusatório e inquisitivo, vez o texto legal possibilita ao magistrado inúmeras interpretações subjetivas aos casos em que julga, e esse subjetivismo jurídico já se atrela a um sistema acusatório deformando o seu objetivo fim. 
3 A AUSÊNCIA DE CRITÉRIOS OBJETIVOS PARA A UTILIZAÇÃ̃O DA PROVA ILÍCITA POR DERIVAÇÃO

No que tange às provas ilícitas e provas ilícitas por derivação, como verificado, sua vedação foi introduzida na reforma, ficando positivada no artigo 157 do Código de Processo Penal, sendo a inadmissibilidade da prova uma sanção, matéria prevista na mudança.

Observa-se que, ao reformular o citado artigo, operou-se o saneamento de uma omissão histórica existente no ordenamento jurídico brasileiro. Há muito tempo já deveria ter sido prevista a vedação das provas ilícitas na legislação infraconstitucional, pois consiste em matéria tão importante na proteção do cidadão, lidando com elementos constitucionais fundamentais.

Até a vigência da Lei que modificou o Código de Processo Penal, a matéria só havia sido enfrentada jurisprudencialmente, numa aplicação subjetiva das questões atinentes a este estilo de prova, tendo sido posição majoritária do Supremo Tribunal Federal (MORAES, 2002, p. 127-128).

Antes da reforma constitucional de 1988, o Supremo Tribunal Federal já havia albergado a teoria norte americana dos frutos da árvore envenenada. Exemplo disso, em caso julgado no RTJ, n¹22/47, o relator, além de desentranhar as provas obtidas por gravações clandestinas, mandou trancar o inquérito policial, por falta de provas que originassem a investigação (GRINOVER, 2011, p. 134).

Observa-se que a referida Lei criou previsão legal sobre as matérias atinentes à prova ilícita por derivação, visto que inexistia sequer, qualquer abordagem da matéria sobre prova ilícita no Código de Processo Penal. Assim, o objetivo central é regular suas formas de afastamento e utilização (CHOUCKR, 2009, p. 329).
No tocante à prova ilícita por derivação, se desvela uma das problemáticas da nova Lei, pois regulou a matéria, no âmbito do Código de Processo Penal, de forma totalmente aberta, porquanto possibilitou duas formas que afastam a contaminação da prova, tendo como inspiração o direito norte-americano. Porém, não definiu bem o modo de reconhecimento da derivação, no primeiro e segundo parágrafo do já ventilado dispositivo legal.

Assim, como definiu Fauzi Hassan Choukr "'autonomia das fontes' acabou sendo reconhecida pela nova norma, nada obstante a conceituação do termo ser imprecisa na redação sancionada" (CHOUCKR, 2009, p. 329).

Nos parágrafos do citado artigo pode ser observado que as provas ilícitas por derivação poderão ser aceitas se não evidenciado nexo de causalidade entre a primeira prova e a derivada (teoria do encontro fortuito), como também, a teoria da fonte independente (MANZANO, 2010, p. 338-339).

Neste ponto o legislador brasileiro equivocou-se. Em relação à teoria da fonte independente, no parágrafo segundo do artigo 157 do Código de Processo Penal, misturou aquela teoria com a teoria da descoberta inevitável (Inevitable discovery execption), pois, a independência da fonte não está atrelada com a descoberta inevitável da prova, aquela tem como objetivo a demonstração de que a prova não possui dependência com a prova contaminada (OLIVEIRA, 2010, p. 318).

A realidade é que o legislador se refere à limitação da descoberta inevitável, pois o conceito positivado no citado artigo remete à teoria da descoberta inevitável, porém nomeando erroneamente quando refere "fonte independente" (LIMA, 2012, p. 882).

Assim, ambos os parágrafos do dispositivo legal problematizam a prova derivada, uma vez que ampliam a margem de interpretações sobre o que é derivação ilícita, constituindo uma 
verdadeira abertura para qualquer utilização e conceituação de prova pelos tribunais pátrios.

Como bem referiu Eugênio Pacelli de Oliveira, existem dificuldades para a definição de derivação, fazendo-se presente na identificação concreta de se tratar de prova efetivamente derivada da ilícita, assim busca-se o significado de nexo de causalidade prova (OLIVEIRA, 2010, p. 318).

Ainda, Aury Lopes Jr. preleciona que, a reforma é pouco clara acerca do nexo de causalidade que define a contaminação, como também, sobre a teoria da fonte independente. Consistindo em disposições vagas e imprecisas, originando aberturas perigosas, utilizando como exemplo a afirmativa "trâmites típicos e de praxe, próprios da investigação ou instrução criminal". Define de forma contundente ser uma porta aberta para que o magistrado possa legitimar qualquer ação que limite a eficácia do princípio da contaminação (LOPES JR., 2009, p. 10).

De mesma banda, alicerçou Ada Grinover Pellegrini que o legislador ao elaborar o texto desta forma, abriu portas para que, utilizando-se do fundamento citado, qualquer prova derivada possa ser convalidada (GRINOVER, 2011, p. 135).

Cita como exemplo, uma confíssão obtida mediante tortura, onde o suspeito indica o local onde se situa uma prova documental. Realiza-se busca e apreensão, respeitando-se todas as formalidades do ato, apreendendo-se o referido documento. A teoria da ilicitude da prova chancelaria a carga proibitória, devendo ser desentranhadas dos autos as provas obtidas, mediante a aludida diligência. Porém, em virtude do parágrafo segundo, do artigo 157, do Código de Processo Penal, tal elemento probatório poderia ser utilizado, não sendo necessário, nem mesmo que tal prova derivada fosse conseguida de forma regular, bastando tão somente que existisse a efetiva possibilidade de que isso acontecesse. Tudo isso pela possibilidade da análise subjetiva do julgador. (GRINOVER, 2011, p. 135).

Ao contrário do que prescreve os já citados doutrinadores, discorda Andrey Borges Mendonça, ao analisar o dispositivo legal, entende que não haverá prejuízos quanto a sua aplicação, uma vez que o magistrado deverá fundamentar a aceitação da prova ilícita derivada, o que restringiria a amplitude da restrição das provas, não transbordando para uma inconstitucionalidade (MENDONÇA, 2009, p. 168-171).

Portanto, a Lei elevou o entendimento do magistrado para o reconhecimento do alcance da ilicitude da prova derivada, devendo observar o grau de vínculo existente entre a primeira e a segunda prova, conseguinte afastando-se o nexo entre elas, estará afastada a ilicitude da prova (TÁVORA, 2010, p. 354).

Porém, filiamo-nos com a ideia de que, mesmo com uma decisão fundamentada nos fatos, existe uma amplitude interpretativa que remete imensos poderes ao magistrado, visto que a fundamentação poderá ser erigida formalmente legal e constitucional. Contudo, ao visitarmos o plano de fundo desta decisão, em uma análise maior e mais qualificada, aquilo que pareceria correto, no entanto, cinge-se em ilicitude. Percebendo-se a duvidosa constitucionalidade do texto legal em estudo (PITOMBO, 2008, p. 20).

Em semelhante posição, Augusto Jobim do Amaral reconhece que a criação das regras de exclusão da contaminação como o "nexo causal" e a "fonte independente", todas apresentam-se vagas e imprecisas, conceitos estes que anulam por completo a configuração da prova ilícita por derivação (AMARAL, 2014, p. 452).

Exemplo disso são as inúmeras reformas de decisões que se observa dia após dia nas superiores instâncias de nossos tribunais pátrios, as quais apenas nos demonstram uma amostragem dos desmandos interpretativos 
realizados em um país com a cultura inquisitiva, com sede de punição e carcerização.

Nesta trama, tem-se que o nexo de causalidade da prova como ilicitude, será avaliado pelo alvedrio do magistrado, decidindo nos casos concretos se existe ou não relação com as provas coligidas nos autos, como também, observará a possibilidade da obtenção por fonte independente das primeiras provas (SILVA, 2008, p. 13).

\section{O RETROCESSO DO TEXTO LEGAL EM DESACORDO COM AS GARANTIAS CONSTITUCIONAIS EM UM ESTADO DEMOCRÁTICO DE DIREITO: AS CONSEQUÊNCIAS DA AUSÊNCIA DE CRITÉRIOS}

O dispositivo legal reformado em nada modificou o entendimento da matéria, continuando com a subjetividade advinda da compreensão dos tribunais sobre a teoria dos Frutos da Árvore Envenenada.

Tem-se, portanto, uma regressão ao velho e antiquado subjetivismo dado ao juiz, que é transformado num verdadeiro Deus, pois sua apreciação, que na maioria das vezes é eivada de interpretações próprias, vai decidir se tal prova que foi ilicitamente derivada poderá ou não ser utilizada.

Isso transmuta a ideia do velho processo inquisitivo, uma vez que, ao alvedrio do magistrado, poderiam ser utilizadas provas proibidas, ou que fustigam direitos constitucionais fundamentais. Neste ponto Jacinto Nelson Coutinho (COUTINHO, 2008, p. 13) insurge-se, afirmando que:

Não se salva da inconstitucionalidade nem o novo texto do artigo 157, o qual aterra no âmbito infraconstitucional a regra do art. 5, LVI, CR ("são inadmissíveis, no processo, as provas obtidas por meios ilícitos"), tentando explicitar a proibição à prova ilícita, como se para ganhar vida a Constituição fosse preciso uma reforma no CPP, algo muito próprio de um Brasil Profundo em matéria de respeito a aplicação das leis.

Portanto, verificou-se um grave problema quanto às hipóteses probatórias, pois, embora exista a vedação de sua utilização, a Lei propiciou aos magistrados uma ampla aceitação das hipóteses de cabimento da prova por derivação, ocorrendo a problemática de que, a critério do julgador, qualquer prova possa ser aceita, sendo uma análise deveras subjetiva, o que transgride os princípios constitucionais de ampla defesa e contraditório (EBERHARDT , 2009, p. 111).

$\mathrm{Na}$ discussão, podemos observar divergências, tanto no que tange aos limites impostos aos magistrados, quanto ao conceito de prova ilícita por derivação, e qual sua possibilidade de aceitação, tendo como principal referencial teórico a teoria Norte Americana do Fruto Envenenado (OLIVEIRA, 2011, p. 349).

Importante avaliar se as exceções previstas em Lei para a admissibilidade da prova ilícita por derivação fragilizam e esvaziam a garantia da vedação da prova ilícita, permitindo sua utilização no processo penal.

A indeterminação e ausência de parâmetros para a análise desta fonte independente, como também, da configuração de descoberta inevitável, onde, como já foi visto, exige-se parcimônia do intérprete da Lei, esvazia todas as garantias objetivadas (MOREIRA, 2008, p. 49).

Aqui, observa-se claramente que estes conceitos indeterminados, que ferem diversos princípios, criam restrições não abordadas pelo texto constitucional, determinando que o complemento da indeterminação verificada seja feito pelo julgador (COUTINHO, 2008, p. 13).

Nesta mesma senda, o doutrinador Miguel Tedesco Wedy (WEDY, 2009, p. 164-165) alicerça que a maior problemática da Lei está inserida no que prevê a descoberta inevitável, expondo que "A abertura desse conceito permite 
a previsão de que aqui verdadeiramente poderão ter sido 'escancaradas às porteiras' para adoção da prova ilícita por derivação."

Acrescentou, ainda, que no caso concreto, instituir a possibilidade de obtenção de tal prova pelos meios usuais, deflagra uma benção a busca e coleta da prova ilícita por derivação, como regra na investigação. Concluindo que, será muito mais fácil a busca da prova derivada da ilícita, e posteriormente, com o fato consumado, concluir que esta prova poderia ser obtida por outros meios "típicos e de praxe" (WEDY, 2009, p. 164-165).

Nesse mesmo panorama alicerçou Maria Elizabeth Queijo, afirmando existir um grande risco na adoção das citadas exceções quanto à utilização de prova ilícita por derivação, pois estimularia a utilização de expedientes ilícitos para persecução da prova, diante da possibilidade de sua utilização, mesmo com as consequências no âmbito penal em relação a essa conduta do agente na produção da prova (QUEIJO, 2008, p. 19).

Portanto nesse ponto, filiamo-nos com a doutrina de Miguel Tedesco Wedy, fundamentando a ideia de que a melhor alternativa para o legislador consistiria na vedação total da prova derivada da ilícita, evitando a fragilização das garantias quanto à produção e introdução de provas ao processo, de forma a limitar o exercício do poder estatal, observando o histórico abuso do Estado Acusador (WEDY, 2009, p. 164-165).

No mesmo sentido Marcos Eberhardt elucidou que, apesar das mudanças pontuais de grande relevância, ocorreu um reforço considerável ao viés inquisitivo em que sempre foi submetido o Código de Processo Penal, inflamando a ideia de que, mesmo com as mais de duas décadas já passadas da promulgação da Constituição Federal Pátria, esta ainda é lida a partir do antiquado código, o que, por evidente, deveria ser ao contrário (EBERHARDT, 2009, p.
111).

Neste ponto, cinge-se uma curiosidade, pois a Lei, sobre a matéria da proibição de provas ilícitas, deveria positivar no texto infraconstitucional o preceito trazido pela carta magna em seu artigo $5^{\circ}$, inciso LVI, mas acaba positivando o desrespeito ao preceito elencado.

Assim, sobre qual ideologia que deverá ser implementada a interpretação sobre a constitucionalidade da reforma legal estudada em pilastras de democracia ou autoritarismo, em um prisma de garantismo ou velho utilitarismo filiamo-nos no que ensina Aury Lopes Jr. (LOPES JR, 2014, p. 33-34), que, após realizar importante reflexão sobre o trabalho de James Goldschmidt, formulou o seguinte entendimento, in verbis:

A uma constituição autoritária corresponderá um
processo penal autoritário, utilitarista (eficiência
antigarantista). Contudo, a uma constituição
democrática, como a nossa, necessariamente deve
corresponder um processo penal democrático e
constitucional".

Aqui retomamos o debate sobre a abertura e o subjetivismo em um contexto brasileiro, como já foi explanado, uma vez que o panorama de permanência das pulsões inquisitoriais se arvora mesmo em períodos democráticos, sendo preservada a postura conservadora dos atores jurídicos com relação à repressão penal (no nosso caso preocupamo-nos com os juízes), fomentando uma expansão do encarceramento, sem quaisquer filtros à demanda punitiva (AMARAL, 2014, p. 341).

Sobre este aspecto, Augusto Jobim do Amaral (AMARAL, 2014, p. 346) sustenta que essa tendência punitivista conservadora, uma espécie de política-criminal, também é replicada na Magistratura.

O populismo penal inebria também o exercício da jurisdicionalidade, situação demonstrada a partir de uma pesquisa realizada em meados de 2006 pela Associação dos 
Magistrados Brasileiros (AMB), com cerca de 3 mil juízes (25, $1 \%$ do total de magistrados), demonstrou uma tendência maciça da magistratura nacional em potencializar $\mathrm{o}$ punitivismo legislativo (AMARAL, 2014, p. 346).

Necessária, portanto, uma reflexão sobre a abertura que recaí à prova ilícita derivada - isso que nem adentramos o debate sobre a divisão entre as nulidades absolutas e relativas que preponderantemente se confundem com as ilícitas, aceitas frequentemente como elementos de convicção à condenação - tendo em vista este condicionamento institucional/cultural encrustado no cargo de Estado Juiz.

Nesse sentido, isso vai completamente à contramarcha à função deliberada ao direito e processo penal pelo liberalismo - em sua pretensão emancipatória de criar um Estado que respeitasse os direitos humanos. Isto é, um sistema processual que criasse barreiras ao poder de punir, limitando ao máximo sua intervenção (CARVALHO, 2008, p. 485).

Salo de Carvalho aduz que (CARVALHO, 2008, p. 485):

Ao Estado liberal, portanto, é auferida a responsabilidade de limitar duas formas diversas de agressão, dois distintos desejos (vontades) de violência: violência privada [...]; violência pública, verificável no abuso de poder (vontade de punição) das agências repressivas do lupus artificialis quando dos exercícios legítimos (Weber) ou ilegítimos (direito penal subterrâneo ou do terror) das violências.

Complementa o autor, afirmando que esta função primária em um Estado Moderno foi transmutada, ocorrendo uma reviravolta, contrariando toda a construção anterior iniciada com Beccaria, dentre outros. Ocorreu de fato uma inversão naquilo que deveria ter um caráter limitador, edificando o Direito Penal e Processo Penal como baluarte de tutela de direitos, uma "pantomima" moderna para solucionar as diversas questões relativas à criminalidade (CARVALHO, 2008, p. 507).

Assim, Salo de Carvalho vai elencar que "No campo da teoria processual penal, os efeitos do feitichismo legalista em termos de violação das regras do jogo (garantias processuais dos acusados) são inequívocos, demonstrando a extensão e os efeitos perversos do enunciado" (CARVALHO, 2008, p. 511).

Sobre esse ponto, ainda elenca que a questão das nulidades seria a uma das mais sensíveis no interior dos sistemas penais de garantias. Assim, esse sistema cria uma gama de garantias como barreira de contenção ao transbordo punitivo, exatamente pela tendência de sistemas punitivos - com o nosso - em se aproximar do inquisitorialismo, revelando e efetivando seu sentimento mais puro: a vontade de punição (CARVALHO, 2008, p. 511-512).

Neste prisma, a harmonização dos sistemas de garantias com os postulados dos direitos humanos impõe a necessidade de que se inverta a lógica que permeia a legislação penal. A flexibilização ou desconsideração das normas de garantia devem sempre ensejar nulidade - aqui podemos interpretar de acordo com a ilicitude derivada matéria em estudo (CARVALHO, 2008, p. 512).

No mesmo sentido Giacomolli aventa que (GIACOMOLLI, 2014, p. 164) “As limitações à prova inserem-se na perspectiva da evolução da teoria da prova na esfera criminal, a qual se direciona na consideração do ser humano como sujeito de direitos e deveres, não como objeto desnudo da intervenção do aparato criminal do Estado".

Com isso, verifica-se de mesma maneira, que a abertura legal apenas escancarou uma brecha para que esse "feitichismo" pela punição, que a solução mágica do cárcere possa ser empregada de forma legal e subsidiada em discursos subjetivos - um tipo de estelionato legal da vedação constitucional pela deformidade 
discursiva e legal.

Nesse passo, impossível não citar a brilhante passagem de Rui Cunha Martins (MARTINS, 2013, p. 89-91), quando analisa a presença de mecanismos ditatoriais em um ambiente de democracia, in verbis:

\begin{abstract}
A complexidade de maior parte das situações deste gênero deriva de os regimes políticos em causa serem, em simultâneo, democracias, pelo menos no sentido em que dão assistência às modalidades formalmente reconhecidas para tal, recorrendo embora, pontualmente e com um pragmatismo cirúrgico (eu diria que no âmbito de uma lógica de puro consumo, indicadora de que o capitalismo é cada vez mais a estética política da democracia), ao patrimônio da ditadura para "cobrir" necessidades que não podem, geneticamente, encontrar resposta legítima no painel de qualificações, mecanismos e propriedades disponíveis da democracia.

[...] O fato de um sistema democrático fazer uso de mecanismos constantes do painel de funcionalidades da ditadura que dizer exatamente isso, que ele se dispõe a trabalhar com formas ditatoriais, não podendo querer dizer que em caso algum que, por via da sua requisição por parte de um sistema democrático, essas formas ditatoriais se "democratizaram". "Fascismos" em ambientes democráticos? Sim. Fascismos punitivos, fascismos societais, fascismos informativos.

[...] A fronteira entre ditadura e democracia não é dada pela sucessividade do tempo histórico, desenha-se nas práticas, isto é, nas decisões políticas.
\end{abstract}

Assim, por fim, a nova Lei nada trouxe de novo, manteve a prática "ditatorial”, a abertura punitiva e conservadora, apenas serviu como legitimação e positivação do pensamento do Superior Tribunal Federal sobre a matéria, com seus vícios e demais fatores e lógicas.

\section{CONCLUSÃO}

A subjetividade para o reconhecimento da ilicitude da prova é comprovadamente perigosa, pois certamente a carga decisória impingida produzirá seus alicerces no instinto judicial da justiça vinculados à velha ideia da verdade real e da prevenção de impunidade, o que macula completamente a concepção que se pretende preservar, o respeito às garantias constitucionais fundamentais.

A positivação da norma que relativiza a contaminação da prova, nada inovou nos tribunais pátrios, visto que, antes mesmo da reforma, já eram utilizadas jurisprudencialmente teorias importadas do direito norte-americano.

Observa-se que, mesmo com a introdução legal da matéria que relativiza a contaminação das provas, não foram sanados os problemas percebidos na sua utilização, pois a reforma do dispositivo legal, como já foi abordada, não define bem o alcance desta relativização, nem mesmo mecanismos seguros de seu reconhecimento.

Assim, nada mais certo do que declararse inconstitucional a possibilidade legal de relativização aventada em relação às provas ilícitas por derivação, pois o dispositivo constitucional prevê a proibição da prova ilícita, e consequentemente todos os efeitos que advirem da mesma.

Portanto, todos os alicerces constituídos com uma introdução de prova ilícita deveriam ser desentranhadas dos autos, ou, a decretação da nulidade total do processo, quando este, tiver o ponto de partida de prova ilícita.

Deste modo, mesmo que a doutrina utilize-se de argumentos para possibilitar a utilização da prova ilícita por derivação, ou mesmo agora, com o texto legal regulando a matéria, ainda não ocorreu uma conceituação segura quanto à problemática de sua relativização, e, enquanto isso não ocorrer, enquanto a decisão for limitada ao plano subjetivo do julgador, tal relativização não poderá ser utilizada, pois sempre estará viciada pela vontade daquele que aplica a Lei.

Ainda, fere gritantemente o principio da taxatividade e da legalidade, como também da 
reserva legal, pois o estudado artigo de Lei impõe um entendimento próprio do que é prova ilicitamente derivada para cada caso concreto.

Por fim, como já mencionado, a Lei nada trouxe de novo, somente coletou o entendimento jurisprudencial e alocou em forma de texto legal, positivando a matéria que já era abordada no Supremo Tribunal Federal, mantendo o problema existente, só que com outra roupagem.
Assim, como já esposado no discorrer do artigo, a conclusão é de que a estudada reforma deve ser declarada inconstitucional, por ferir inúmeros preceitos constitucionais fundamentais, e ser prejudicial aos cidadãos que ficam a mercê do Estado no Processo Penal, legitimando a disparidade de armas existente.

\section{REFERÊNCIAS}

AMARAL, Augusto Jobim do. Política da prova e cultura punitiva: a governabilidade inquisitiva do processo penal brasileiro contemporâneo. São Paulo: Almedina, 2014.

AVILA, Gustavo Noronha; GAULAND, Dieter Mayrhofer; FILHO, Luiz Alberto Brasil Simões Pires. A obsessão pela "verdade" e algumas de suas consequiências para o processo penal. In: CARVALHO, Salo; AZEVEDO, Rodrigo Ghiringhelli. (Orgs.). A Crise do Processo Penal e as Novas Formas de Administração da Justiça Criminal. 1. Ed. Porto Alegre: Notadez, 2006.

AVOLIO, Luiz Francisco Torquato. Provas Ilícitas Interceptações telefônicas ambientais $e$ gravações clandestinas. 3. ed. São Paulo: R. dos Tribunais, 2003.

BARROS, Flaviane de Magalhães. (Re)forma do Processo Penal Comentários críticos dos artigo modificados pelas Leis n. 11.960/08, n. 11.719/08 e n. 11.900/09. 2. ed. Belo Horizonte: Dle Rey, 2009.

CARVALHO, Salo de. Criminologia, Garantismo e Teoria Crítica dos Direitos Fundamentais Humanos: Ensaio sobre o exercício dos poderes punitivos. In: MARTINEZ, Alejandro Rosillo. (Org.). Teoria Crítica dos direitos humanos no século XXI. Porto Alegre: EDIPUCRS, 2008.

CARNELUTTI, Francesco. Lições sobre o processo penal. Tradução de BRUNO Francisco Galvão. 1. ed. v. 1. Campinas: Bookseller, 2004.

CHOUKR, Fauzi Hassan. Código de Processo Penal: Comentários consolidados e crítica jurisprudencial. 3. ed. Rio de Janeiro: Lumen Juris, 2009.

COSTA ANDRADE, Manuel da. Sobre as Proibições de Prova em Processo Penal. Coimbra: Coimbra, 1992.

COUTINHO, Jacinto Nelson de Miranda. As Reformas Parciais do CPP e Gestão da Prova: Segue o Princípio Inquisitivo. Boletim IBCCrim, v. 16, n. 188, jul. 2008.

EBERHARDT, Marcos. Reformas Processuais Penais no Âmbito da Produção Probatória. In: NUCCI, Guilherme de Souza (Org.). Reformas no processo penal. Porto Alegre: Verbo Jurídico, 2009.

FARIAS, Vilson. Considerações em torno da Lei 11.690 de 09.06.2008. Revista dos Tribunais, São 
Paulo, ano 99, v. 896, p. 01-800, jun. 2010.

FEITOZA, Denílson. Direito Processual Penal: Teoria, Crítica e Práxis. 5. ed. Niterói: Editora Impetus, 2008.

GERSON, Fernando. Apontamentos críticos sobre as reformas processuais penais. In: CALLEGARI, André Luís; WEDY, Miguel Tedesco (Orgs.). Reformas do Código de Processo Penal. 1. ed. Porto Alegre: Livraria do Avogado Editora, 2009.

GOMES FILHO, Antonio Magalhães. Direito À Prova No Processo Penal. 1.ed. São Paulo: R. dos Tribunais, 1997.

GIACOMOLli, Nereu José. Reformas(?) Do Processo Penal Considerações Críticas. 1. ed. Rio Janeiro, 2008.

O Devido Processo Penal Abordagem Conforme a Constituição Federal e o Pacto de São José da Costa Rica. São Paulo: Atlas, 2014.

GLOECKNER, Ricardo Jacobsen. Um Nova Teoria das Nulidades: Processo Penal e Instrumentalidade Constitucional. Tese (Doutorado em Ciências Jurídicas)- Faculdade de Direito, Setor de Ciências Jurídicas, Universidade Federal do Paraná, Curitiba, 2010.

GRINOVER, Ada Pellegrini. As nulidades no processo penal. 12. ed. São Paulo: R. dos Tribunais, 2011.

HOLMES JR, Oliver Wendell. Opinião. Silverthone Lumber Co. v. United States, 251US385, 392, 1920. Disponível em: <www.findlaw.com/casecode/supreme.html>. Acesso em: 29 jul. 2005.

LIMA, Renato Brasileiro de. Manual de Processo Penal. 2. ed. v. I. Niterói: Impetus, 2012.

LOPES JR., Aury. Bom Para Quê(M)? Boletim IBCCrim, São Paulo, v.16, n.188, p.01-29, jul. 2008. 2014. Direito Processual Penal e sua conformidade constitucional. 11. ed. São Paulo: Saraiva, GLOECKNER, Ricardo Jacobsen. Investigação Preliminar no Processo Penal. 6. Ed. São Paulo: Saraiva, 2014.

MALATESTA, Nicola Framarino Dei. A lógica das provas em matéria criminal. Tradução de Paolo Capitanio. 2. ed. Campinas: Bookseller, 2001.

MANZANO, Luís Fernando de Moraes. Curso de Processo Penal. São Paulo: Atlas, 2010.

MARTINS, Rui Cunha. O ponto cego do direito penal. 3. ed. São Paulo: Atlas, 2013.

MENDONÇA, Adrey Borges de. Nova Reforma do Código de Processo Penal Comentadas - artigo por artigo. 2. ed. Rio de Janeiro: Mendonça, 2009.

MORAES, Alexandre de. Direito Constitucional. 12. Ed. São Paulo: Atlas, 2002. 
MOREIRA, Reinaldo Daniel. A reforma do Código de Processo Penal e a Nova Disciplina Legislativa da Prova. Revista Jurídica Consulex, Ano XII, nº 275, 30 de jun., 2008.

NUCCI, Guilherme de Souza. Código de Processo Penal Comentado. 9. ed. São Paulo: RT, 2009.

OLIVEIRA, Eugênio Pacelli de. Curso de Processo Penal. 14. ed. Rio de Janeiro: Lumen Juris, 2011.

. FISCHER, Douglas. Comentários ao Código de Processo Penal e sua Jurisprudência. 1. ed. Rio de Janeiro: Limen Juris, 2010. p. 318.

PRADO, Geraldo. Prova penal e sistema de controles epistêmicos: a cadeia de custódia das provas obtidas por métodos ocultos. São Paulo: Marçal Pons, 2014.

PRADO, Geraldo; CASARA, Rubens R. R. Eficientismo repressivo e grantismo penal: dois exemplos de infenuidade na seara epistemológica. Discursos Sediciosos, crime, direito e sociedade, Ano 17, n. $^{\circ}$ 19/20, $1^{\circ}$ e $2^{\circ}$ sem., 2012.

PITOMBO, Cleunice Valentim Bastos. Considerações Iniciais Sobre a Lei. 11960/08. Boletim IBCCrim. v. 16, n. 188, jul. 2008. p. 20.

QUEIJO, Maria Elizabeth. O Tratamento da prova ilícita na reforma processual penal. Boletim IBCCrim. v. 16, n. 188, jul. 2008

$O$ direito de não produzir prova contra si mesmo: $O$ princípio do nemotenetur se detegere $e$ suas decorrências no processo penal. 1. ed. São Paulo: Saraiva, 2003.

RAMOS, João Gualberto Garcez. Curso de processo penal norte-americano. 1. ed. São Paulo: R. dos Tribunais, 2006.

SAMPAIO, José Adércio Leite. Direitos Fundamentais. 2. ed. Belo Horizonte: Del Rey, 2010.

SILVA, Ivan Marques da. Reforma Processual Penal de 2008, procedimentos penais: Lei 11.690/2008, provas: Lei 11.690/2008, júri: comentadas artigo por artigo. São Paulo: Revista dos Tribunais, 2008.

TASSE, Adel El. MILEÓ, Eduardo Zanoncini. PIASECKI, Patrícia Regina. O Novo Sistema de Provas no Processo Penal. Comentários à Lei $n^{\circ}$ 11.960/2008. Curitiba: Juruá, 2009.

TÁVORA, Nestor. ALENCAR, Rosmar Rodrigues. Curso de Direito Processual Penal. 4. ed. Salvador: Editora Jus Podivm, 2010.

WEDY, Miguel Tedesco. A sistemática da prova na reforma do processo penal. In: CALLEGARI, André Luís; WEDY, Miguel Tedesco (Orgs.). Reformas do Código de Processo Penal. 1. ed. Porto Alegre: Livraria do Avogado Editora, 2009.

Recebido em: 03/03/2016 Aceito em: 20/11/2016 
